\title{
Learners' experience and perceived impact of a health literacy program in adult basic education: a qualitative study
}

\author{
Danielle M Muscata ${ }^{a}$ Suzanne Moronya ${ }^{a}$ Don Nutbeam ${ }^{\text {, Julie }}$ Ayre ${ }^{a}$, \\ Heather L Shepherd ${ }^{b, c}$, Sian K Smith ${ }^{d}$, Haryana M Dhillon ${ }^{c}$, \\ Andrew Hayen ${ }^{e}$, Karen Luxford ${ }^{\dagger}$, Wedyan Meshrekyg and \\ Kirsten McCaffery ${ }^{a, h}$
}

a Sydney Health Literacy Lab, School of Public Health, Faculty of Medicine and Health, University of Sydney, NSW, Australia

b School of Public Health, Faculty of Medicine and Health, University of Sydney, NSW, Australia

c School of Psychology, University of Sydney, NSW, Australia

a Psychosocial Research Group, Prince of Wales Clinical School, Faculty of Medicine, UNSW Sydney, Australia

e Faculty of Health, University of Technology Sydney, NSW, Australia

${ }^{\dagger}$ Clinical Excellence Commission, Sydney, NSW, Australia

${ }^{g}$ NPS MedicineWise, Sydney, NSW, Australia

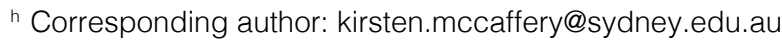

\section{Article history}

Publication date: June 2020

Citation: Muscat DM, Morony S, Nutbeam D, Ayre J, Shepherd HL, Smith SK, Dhillon HM, Hayen A, Luxford K, Meshreky W, McCaffery K. Learners' experience and perceived impact of a health literacy program in adult basic education: a qualitative study. Public Health Res Pract. 2020;30(2):e29231909. First published 29 August 2019. https://doi.org/10.17061/ phrp29231909

\section{Abstract}

Objectives and importance of the study: Adult literacy programs aim to empower learners to participate more effectively in everyday life. This includes programs with health content embedded in curricula to target health literacy. Adult learners who attend these programs represent a heterogeneous population, but include a high proportion of hard-to-reach or socially disadvantaged groups in terms of age, ethnicity, educational background, language and prevalence of learning disabilities. In 2014, we conducted a cluster-randomised controlled trial of a health literacy program in adult basic education classes across New South Wales, Australia. This paper reports findings from a qualitative study exploring learners' experience of the course and its perceived impact on their lives, as well as their understanding and confidence about health.

Study type: Qualitative interview study.

Method: We conducted semistructured interviews as part of the evaluation of the 18-week health literacy program, with participants purposively recruited from six health literacy classes $(n=22)$. Researchers trained in qualitative methods interviewed adult learners either face to face or over the phone using a topic guide. Data was analysed using the Framework method, a matrixbased approach to thematic analysis.

Results: The majority of interviewees were female, lived in metropolitan areas and were from non-English-speaking backgrounds. Most had existing self-reported health problems and inadequate functional health literacy. 


\section{Key points}

- Participants in adult basic education classes in New South Wales, Australia, described positive impacts of a health literacy course on their language, literacy and numeracy skills, functional health literacy skills, and health knowledge

- Participants reported that sharing health-related experiences facilitated a supportive learning environment, enabled them to more easily engage in classroom activities, and increased their confidence to interact with others in the broader community

- Learners reported transferring new health knowledge into their home and wider social network
Most participants described positive impacts of the health literacy course on their language, literacy and numeracy skills, functional health literacy skills, and health knowledge. They also reported being able to translate this into health actions including interacting with providers, accessing and using healthcare, and managing health and illness (e.g. making healthier food choices). Learners also described positive social outcomes of the course, including feelings of connectedness and interpersonal trust within a new network of learners, and reported sharing new knowledge with others in their communities.

Conclusions: The findings add value to existing limited evidence that has demonstrated the untapped potential of adult basic education to develop health literacy skills among socially disadvantaged groups. Learners valued the opportunity to share experiences in structured group learning, and reported confidence to transfer new knowledge into their home and wider social network

\section{Introduction}

Health literacy represents a modifiable health determinant that can be improved through education ${ }^{1}$ to achieve effective use of the healthcare system, good self-care and improved health. ${ }^{2}$ Incorporating health literacy in adult basic education curricula offers a promising method of building health literacy capacity within the community by leveraging existing infrastructure and resources. ${ }^{3-5}$ The importance of doing so is reinforced by the high prevalence of low health literacy in developed countries (e.g. $60 \%$ of the adult Australian population ${ }^{6}$ ), the disproportionate impact on culturally and linguistically diverse groups ${ }^{6}$, and the fact that lower health literacy is an independent predictor of poorer health outcomes. ${ }^{7}$

Limited available evidence suggests that embedding health literacy into adult basic education can improve learners' functional health literacy, as well as health knowledge ${ }^{4,5,8-10}$ and self-efficacy. ${ }^{10}$ Reported improvements in health behaviours from such programs include increased physical exercise ${ }^{7}$, a healthier $\operatorname{diet}^{7,8,10}$, and improved interactions with the health system including scheduling appointments, describing symptoms and following medical advice. ${ }^{10}$ However, health content is often incorporated into adult basic education curricula on an ad hoc basis, and programs have limited topic coverage to focus on these outcomes. This may represent a missed opportunity for learners to develop more generic skills to support effective communication, access to health services and patient empowerment. ${ }^{11}$

Here we report the findings of a qualitative interview study carried out as part of a cluster-randomised controlled trial of a health literacy program delivered in adult education settings in New South Wales (NSW) Australia. ${ }^{12}$ Qualitative methodologies were employed to gain a broader understanding of program impacts from the perspective of participants, with specific aims to examine: 1) learners' experience of the course; and 2) its impact on their lives, and health-related understanding and confidence.

\section{Method}

\section{Ethics approval}

The University of Sydney Human Research Ethics Committee (protocol number: 2013/938) and each participating institute of Technical and Further Education (TAFE) approved this study.

\section{Design}

Qualitative semistructured interview study conducted as part of a larger cluster-randomised controlled trial of a health literacy program delivered in adult education settings (TAFE NSW).

\section{Program content}

Learners completed approximately 18 weeks of language, literacy and numeracy (LLN) classes as part of an existing adult basic education program, covering either health or non-health (standard LLN) content. See McCaffery et al. ${ }^{12}$ for full details of the program. The health literacy program had 31 topics (Table 1). Some health literacy classes $(n=4)$ were visited by local community health providers, although logistical issues made this the exception. ${ }^{13}$ 
Table 1. Health literacy topics included in the program

\section{Core units}

Food labels

Taking temperature

Telling your doctor what is wrong

Nutritional information

Talking to your doctor

What is a serve?

Asking questions

Checking medicine labels

Shared decision making

Talking on the telephone

Answering your doctor's

questions

\begin{tabular}{ll}
\hline Elective units & \\
Getting involved & Understanding a diet \\
Watch first aid demonstrations & Completing medical forms \\
Food groups & Drinking enough fluids \\
Follow written instructions & Emergency services \\
Food temperature safety & Heart rate and pulse \\
Prescriptions & Advice from pharmacist \\
Food date safety & Being active \\
Dosage and timing & Saving lives \\
Budgeting & Health workers \\
Immunisation and health & Follow emergency instructions
\end{tabular}

screening

\section{Data collection and analysis}

Information regarding data collection is provided in Supplementary File 1 (available from: hdl.handle. net/2123/20889) using the Consolidated Criteria for Reporting Qualitative Studies (COREQ). Interviews were de-identified and analysed using Framework analysis, with a thematic matrix to organise data. ${ }^{14}$ Two researchers read a sample of de-identified transcripts (familiarisation) and developed a provisional coding framework (identification) based on the research questions and recurrent issues from interviews. The framework was discussed and revised by DM, SM and JA. JA then coded a selection of transcripts and summarised themes (indexing). The framework was revised further by DM, SM and JA, and JA applied the final coding framework to all transcripts (charting).

\section{Results}

\section{Participant characteristics}

Twenty-two learners from six health literacy classes participated in interviews. For demographic and health characteristics see Table 2. The majority were female, lived in metropolitan areas and were from non-Englishspeaking backgrounds. Most had existing self-reported health problems and inadequate functional health literacy.

Using Framework analysis, we identified four key themes: 1) valuing LLN skills as the building blocks for health behaviours; 2) social impacts: opportunities and skills for social interaction; 3) accessing the healthcare system; and 4) the ripple effect - sharing knowledge and skills beyond the program. Participant quotes are followed by an identification number, gender, age and language spoken at home (English [Eng] or language other than English [LOTE]). Learners with the same letter at the end of their ID (e.g. HLL14D and HLL13D) were enrolled in the same class.

Learners were universally positive about the program, frequently describing it as "excellent" and "really good". The majority reported valuing the opportunity to learn, and particularly enjoyed learning about health information directly relevant to their everyday needs. Learners valued being able to receive support from a qualified adult education teacher.

\section{Valuing literacy and numeracy (LLN) skills as the building blocks for health behaviours}

Most adult learners reported feeling their language and literacy skills, including reading fluency and vocabulary, improved as a result of the program. Learners who spoke a language other than English at home placed value on having improved their health-related vocabulary for foods and medical terms, because they perceived it to be associated with improved functional health skills, including the ability to read and comprehend medicine and nutrition labels, medical forms, and other printed health-related materials.

The medicine label ... and the food label [topics], that's what I really like, that one ... because it, it teach us, er, how to understand. That's in your normal life ... how to work out everything, work out problem or work out the question, you can understand from yourself. (HLL1A - F,44,LOTE)

Without prompting, learners also discussed the perceived value of gaining factual health information (e.g. correct food storage methods), which often served to correct existing misperceptions on topics they initially felt well informed about.

It helps out a lot ... you thought you know a lot. But, a lot of things you didn't really know. Some things we didn't know. (HLL12C - F,55,Eng)

Some adult learners articulated that the course had an impact on their health-related behaviours by increasing their focus on health and health issues, and, further, giving them skills and confidence to independently perform health-related tasks they previously found difficult. Most commonly, learners mentioned that they never read labels on packaged 
Table 2. Demographic and health-related characteristics for the interviewed sample $(n=22)^{a}$

\begin{tabular}{|c|c|c|c|}
\hline Characteristic & Category & $n$ & $\begin{array}{l}\% \text { of valid } \\
\text { responses }^{b}\end{array}$ \\
\hline \multirow[t]{2}{*}{ Gender } & Female & 15 & 68 \\
\hline & Male & 7 & 32 \\
\hline \multirow[t]{2}{*}{ Region } & Metropolitan & 17 & 77 \\
\hline & Regional & 5 & 23 \\
\hline \multirow[t]{2}{*}{ Language spoken at home } & English & 7 & 35 \\
\hline & Need help with English & 13 & 65 \\
\hline \multirow[t]{3}{*}{ Employment status } & Employed (full time/part time/self-employed) & 0 & 0 \\
\hline & Not employed, seeking employment & 4 & 22 \\
\hline & Not employed, not seeking employment & 14 & 78 \\
\hline \multirow[t]{4}{*}{ Reason for study } & To find a job & 3 & 14 \\
\hline & Develop work skills & 1 & 5 \\
\hline & For future studies & 5 & 24 \\
\hline & Personal interest/other & 12 & 57 \\
\hline Health Care Card ${ }^{c}$ & Has a Health Care Card ${ }^{c}$ & 16 & 76 \\
\hline Private health insurance & Has private health insurance & 4 & 20 \\
\hline \multirow[t]{2}{*}{ Inadequate functional health literacy } & Newest Vital Sign health literacy screening tool & 17 & 77 \\
\hline & Single Item Literacy Screener ${ }^{d}$ & 16 & 73 \\
\hline Self-reported health & Fair/poor & 13 & 62 \\
\hline \multirow[t]{6}{*}{ Self-reported health problem } & Arthritis & 5 & 23 \\
\hline & Back pain & 9 & 41 \\
\hline & Heart problems & 2 & 9 \\
\hline & Asthma & 2 & 9 \\
\hline & Depression/anxiety & 10 & 45 \\
\hline & Diabetes & 3 & 14 \\
\hline \multirow[t]{3}{*}{ Caring duties } & Carer & 13 & 59 \\
\hline & Children & 12 & 55 \\
\hline & Parents & 2 & 9 \\
\hline \multirow[t]{2}{*}{ Family circumstances } & Live alone & 4 & 19 \\
\hline & Have children & 19 & 86 \\
\hline
\end{tabular}

Mean age 48.3 years (standard deviation 15.3 years)

b Percentages are calculated using the total number of responses for each question, due to missing data for some variables

c Health Care Cards are issued by the Australian Department of Human Services to people who live in Australia and receive government payments, benefits or allowances

d Answered 'sometimes', 'often' or 'always' (categories 3, 4 or 5) to the question: How often do you need to have someone help you when you read instructions, pamphlets, or other written material from your doctor or pharmacy? 
foods or medication before the course, but reported now having the awareness, skills and confidence to check expiry dates, read medication leaflets and inspect nutritional information (particularly for sugars and fats) while shopping. Some learners said that they now make a greater effort to cook, had made changes to how they store food, were more conscious of washing fresh food before eating, and ate more fruits and vegetables.

That was ... yeah, I must admit now when I go to a supermarket I actually do take note of things like that, whereas I never would have before. Wouldn't even cross my mind. But because I enjoyed learning about it in class, now I take notice in the store. (HLL13D - F,35, Eng)

A minority of learners identified tangible benefits of performing new actions for health, including reducing their household costs by reading and comparing food labels.

\section{Social impacts: opportunities and skills for social interaction}

The social impacts of the course emerged as an important theme from the data, with three interrelated subthemes: 1) reducing social isolation; 2) building group cohesion; and 3) fostering learning in a supportive environment.

\section{Reducing social isolation}

The adult literacy environment was reportedly seen as an opportunity to meet new people and reduce social isolation by creating a new network of learners with similar experiences. Many participants reported previously reduced confidence to engage with the broader community because they were self-conscious about their language and literacy skills, or reported they had experienced mental health issues.

I was a hermit. [Laughs] I really was a hermit ... I stayed in my home. But, um, this has gave me great confidence. I can't wait to come back next year. (HLL13D -F,35, Eng)

\section{Building group cohesion}

Learners revealed that discussing personal health experiences strengthened connections among class members, and built a sense of cohesion and common purpose. Participants reported that strong ties between class members were fostered, creating and reinforcing a sense of camaraderie, equality and trust. By sharing personal stories about their health and their previous interactions with the healthcare system, learners said that they came to appreciate the similarities between them and their common ties.

Because I'm the oldest in the class they call me Mum ... You know, l've gone through a lot of things and a lot more situations than them. And, and of course there's a lot where we're all on the same level. (HLL14D - F,65,Eng)

\section{Fostering learning in a supportive environment}

Learners went on to report that, within the context of an encouraging and supportive learning environment, they felt they had a rare opportunity to practice LLN skills and ask questions in a positive and safe place. Many learners mentioned increased confidence to read aloud and speak in front of others.

Everybody was participating well in the class ... Even the younger people in there and that, yeah ... So it was, it was good like that. And ... there was a lot of them there raising questions and things like that. (HLL11C - M,60,Eng)

I've, um, I've got a lot more confidence in what I feel I can do now... At the beginning of the year I would never, ever read out loud. Now I do in class. (HLL13D - F,35,Eng)

\section{Accessing the healthcare system}

Learners also reported increased confidence to engage with people outside of the classroom setting, including healthcare providers. For example, some learners who spoke a language other than English at home were gradually becoming more confident with Englishspeaking doctors, or had started to attend some of their appointments without the help of a family member.

Yeah. Just, my daughter, my son, some go to

the ... he or she is talking to doctor, I am sitting

here ... Now, some time is ... more time I, I

go to doctor is just me ... to the doctor ... this

time ... I, I think, sometime I ... I not use my son.

(HLL4A - M,58,LOTE)

One learner reported that her doctor had noticed a change in her communication skills.

My doctor can understand me better now ... I explain this to my doctor and she, she says, and I asked her if you can understand me better now than you did before? ... And she says yes, she can understand my symptoms when I explain it to her. (HLL10B - F,39,Eng)

Some learners from non-English-speaking backgrounds said that despite improvements in their vocabulary and LLN skills, they still found it challenging to interact with the healthcare system. Many still preferred to visit doctors they could speak with in their native language, and often required a family member to help complete medical forms. Others reported that although they found it easier to ask the doctor questions, it was difficult to understand the answers due to the complexity of the provider's response. A few learners, while acknowledging 
this gap, reported they now felt more comfortable asking the doctor to elaborate when they did not understand.

I tried understand the doctors ... you know, doctor's language ... doctor, er, say some, some word, I can't understand exactly ... I said, what's this mean? ... I ask again, what's this mean? Can you explain for me? ... Can you open a little bit more me ... You know. (HLL 19E - F,54,LOTE)

Another commonly reported barrier to asking health professionals questions was the fear of looking or feeling stupid. Many learners reported that they had grown up believing they did not have a right to ask questions, and that they should accept the authority of others. The course helped learners recognise that they were entitled to ask questions. These attitudes were directly addressed in the course content, but the realisation that others had faced similar difficulties using health services may have contributed to this change in attitude.

Oh, I just find it, it is a mind, it's a mind opener ... For everyone. Look, I find a lot of us go about with a, a closed mind. And we're, we're frightened to talk and fear of maybe making a mistake, or feeling stupid ... Or ... and I think the more it gets out there that, you know, you can ask questions. (HLL14D - F,65, Eng)

In a similar way, learners whose classes covered topics on emergency services and first aid stated that the course had provided them with clearer expectations about how and when to interact with these services. Learners reported feeling more confident to assist others or call for help. In this way, the impact of the course on behaviour appeared to be more than the result of LLN skill development, but also arose from addressing learners' subjective perceptions of the healthcare system. Engaging with topics related to the healthcare system appeared to challenge learners to question their assumptions, and to make services seem more accessible and familiar.

\section{The ripple effect: sharing knowledge and skills beyond the program}

Many learners said they shared the knowledge and skills gained from the course with family and friends. For example, some mentioned they now encourage their friends and family to ask more questions when interacting with the health system.

\section{I was also talking to a friend this month who's in hospital about the course as well. And she kind of raised her eyebrows a bit, oh ... is that right? Um, so I think she's discovered that she can ask the doctor more questions than she was doing herself. (HLL 14D - F,65, Eng)}

Learners with family, particularly those with children, reported feeling an increased feeling of responsibility to not only make changes to their own health, but to teach other family members about health. This was especially true for topics pertaining to diet and nutrition - learners reported emphasising to their families the importance of a healthy diet and developing healthy eating habits.

Yes, yes. 'Cos I've got children and I want to teach them to eat healthy instead of eating out ... Eating out is good, but that's if you're in a hurry ... And you have to eat nutritious food and keep your body working. (HLL9B - F, 46, LOTE)

Consistent with this finding, some learners reported encouraging family members to enrol in the course.

\section{Discussion}

This study sought to examine learners' reflections on a health literacy program embedded within an existing adult basic education course. In our overall sample, many learners had inadequate health literacy and self-reported health problems, and a large proportion were from nonEnglish-speaking backgrounds. Learners perceived that their language and literacy, health knowledge and skills had improved after participating in the course, and these improvements were consistent with and can be matched to the content of the health literacy intervention.

Learners were universally positive about the program. They particularly valued the everyday relevance of the health content as they could use or act on the knowledge and skills learnt in class (e.g. reading medicine and nutritional labels, and interacting with healthcare systems and providers). Learners also valued the social aspects of a group learning environment and the way health topics showcased the common experiences of peers and facilitated the sharing of these experiences in a supportive learning environment. The social support derived from the course was frequently commented on as a positive outcome of participation, and this observation was also made by teachers of the program (reported elsewhere). ${ }^{13}$

Importantly, learners reported that they had become more confident in areas that extended beyond performing the targeted health behaviours, such as engaging in LLN activities in class, and interacting with people in their community. Sharing new knowledge with others in their communities was frequently reported; however, language differences remained an important barrier to engaging with the health system (e.g. talking to a doctor) for some.

\section{Synthesis of findings with other research}

This study forms part of a larger program of work evaluating the impact of our adult education health literacy training program. ${ }^{12,13,15-18}$ Combined, our results add to the growing evidence that adult basic education institutions have potential to develop transferable health literacy skills among socially disadvantaged groups. These qualitative findings further support theories of adult learning, which posit that adult learners are motivated to 
learn when they understand the relevance of the content to their daily lives. ${ }^{19}$ In addition, our analysis has identified the potential social and interpersonal outcomes of health literacy programs delivered in this setting. It highlights the opportunity that adult education courses offer to not only increase the network of relationships and social support held by individuals, but also to change the way they interact with members of existing networks and with (health) institutions. ${ }^{20,21} \mathrm{~A}$ trusting relationship between class members seemed to encourage greater sharing among members, and the practice and development of LLN skills. Thus, it was a mechanism for learning as well as an outcome in and of itself. This was valued by our sample of learners, a large proportion of whom were socially disadvantaged adults from different language backgrounds and/or were unemployed.

Our findings are consistent with previous literature suggesting that learners share health knowledge and health literacy skills with family, friends and community members. ${ }^{22-24} \mathrm{~A}$ small number of community health providers who visited health literacy classrooms within our study similarly noted that learner questions often related to family and friends. ${ }^{13}$ In this way, health literacy can be seen as 'distributed' through family and social networks as learners pass on their health literacy skills ${ }^{25}$, extending the impact of programs beyond the classroom For people with lower health literacy, who are more likely to rely on personal experience and information obtained through lay networks ${ }^{26}$, creating an environment to build those networks has potential to disseminate accurate health information directly to these hard-to-reach groups. However, it is necessary to ensure the information shared with others is correct. Future studies should investigate how and what information is transferred among communities as a consequence of health literacy programs, and how this might compare to other forms of information transfer (e.g. via the internet).

Governments around the world, including Australia, have published policies and strategies designed to improve health literacy in their populations (see, for example, the Australian Commission on Safety and Quality in Healthcare's health literacy national statement ${ }^{27}$ ). Adult basic education classes offer a practical and effective vehicle through which some of the most disadvantaged community members can engage in the development of their LLN skills in ways that also enhance their health literacy. Disappointingly, in Australia, recent vocational training reforms have increased the emphasis on vocational skills in adult basic education, with a "narrow and behaviourist" focus on workplace tasks and roles. ${ }^{28}$ The current research supports a more holistic approach that is able to deliver practical improvements in LLN skills with added health and social benefits. Integrating health literacy into adult education is an opportunity to build the capacity of people to manage and actively participate in their health, and increase the resources which individuals and groups have access to via their networks. There is a clear need to remove the 'institutional silos' separating the education and health sectors to enable them to work towards a common goal of a healthy society and engaged citizenship. Collaboration between health and education experts as well as learners may inform the choice of interventions implemented within adult education and carefully craft programs geared towards the most desirable outcomes. There is unlikely to be a 'one-size-fits-all' solution.

\section{Strengths and weaknesses of the study}

The exploratory, in-depth nature of this study is a strength as it enabled us to gain a broader understanding of program impacts from the perspective of participants, including impacts that are more difficult to measure (e.g. social connections) or not typically captured in quantitative evaluations of effectiveness. This is particularly important in the context of adult basic education where learners' goals, perspectives and definitions of success may not be related to the accountability goals of other stakeholders. ${ }^{29}$

One limitation of this study is that we only interviewed participants from health literacy classes and do not know how much of the observed advantage was a result of the health literacy intervention. We also did not interview participants who dropped out of the program, and our sample differed from the larger randomised controlled trial sample on self-reported employment status and reasons for taking the course. As such, we may have missed the experiences of those who did not find the program useful. However, teachers reported many participants who withdrew from the program obtained employment or moved away which suggests their reasons for non-participation were logistic rather than due to course content.

Finally, interviews were conducted in the English language and some participants were limited in the information they could provide. An iterative process of data checking was employed so that the qualitative data presented did not only reflect the dominant voices of English-speaking participants, but also those of participants who spoke a language other than English at home. Although learner comments were echoed by teachers (and community health providers when they participated $)^{13}$ and were consistent with previous work in this area, results may have differed if interpreters had been used throughout the interview process.

\section{Conclusion}

Adult basic education programs are an appropriate setting for improving health literacy at a community level. Learners, who are often from socially disadvantaged groups, engage enthusiastically with health content that they perceive to be relevant and important to their lives, and report building health-related skills and confidence. 


\section{Acknowledgements}

We would like to acknowledge the contribution of Aisha Khan to the first stage of Framework analysis. We thank the learners and teachers who participated in the trial and qualitative interviews. The project is funded through an Australian Research Council Linkage project grant (number LP130100480). These grants support collaborations between higher education researchers (i.e. University of Sydney) and industry partners - NSW Clinical Excellence Commission, NPS MedicineWise, NSW Health and participating institutes of TAFE NSW.

\section{Peer review and provenance}

Externally peer reviewed, not commissioned. DN is the Editor-in-Chief of Public Health Research \& Practice, and $\mathrm{AH}$ is an Associate Editor. Both had no part in the peer review process for this paper.

\section{Competing interests}

None declared.

\section{Author contributions}

All authors have made substantial contributions to the conception or design of the work; or the acquisition, analysis or interpretation of data. Specifically, KM, DN, SKS, HMD and HLS conceived of the study and its design. DMM and SM conducted the qualitative interviews, and performed the steps of Framework method together with JA. All authors were involved in the analysis and Interpretation of findings.

DMM, SM and JA drafted the manuscript and all other authors revised it critically for important intellectual content. Final approval of the version to be published has been approved by all authors who agree to be accountable for all aspects of the work.

\section{References}

1. Nutbeam D. Health literacy as a public health goal: a challenge for contemporary health education and communication strategies into the 21 st century. Health Promot Int. 2000;15(3):259-67.

2. Smith SA. Promoting health literacy: concept, measurement and intervention [dissertation]. Cincinnati, Ohio: Union Institute \& University; 2009.

3. Jervelund SS, Maltesen T, Wimmelmann CL, Petersen JH, Krasnik A. Ignorance is not bliss: the effect of systematic information on immigrants' knowledge of and satisfaction with the Danish healthcare system. Scand J Public Health. 2017;0(0):1403494816685936.
4. Soto Mas F, Ji M, Fuentes BO, Tinajero J. The Health Literacy and ESL study: a community-based intervention for Spanish-speaking adults. J Health Commun. 2015;20(4):369-76.

5. Shared Intelligence and the Tavistock Institute. Evaluation of the second phase of the Skilled for Health programme. London; 2009 April [cited 2018 July 03]. Available from: www.tavinstitute.org/projects/report-evaluation-of-phasetwo-of-the-skilled-for-health-programme

6. Australian Bureau of Statistics. Health Literacy, Australia, 2006. Canberra, Australia: ABS; 2008 [cited 2019 Jun 5]. Available from: www.abs.gov.au/ausstats/abs@.nsf/ $\mathrm{mf} / 4233.0$

7. Berkman ND, Sheridan SL, Donahue KE, Halpern DJ, Crotty K. Low health literacy and health outcomes: an updated systematic review. Ann Intern Med. 2011;155(2):97-107.

8. Chen X, Goodson P, Acosta S. Blending health literacy with an English as a second language curriculum: a systematic literature review. J Health Commun. 2015;20(sup2):101-11.

9. Santos MG, Handley MA, Omark K, Schillinger D. ESL participation as a mechanism for advancing health literacy in immigrant communities. J Health Commun. 2014;19(sup2):89-105.

10. Chervin C, Clift J, Woods L, Krause E, Lee K. Health literacy in adult education: a natural partnership for health equity. Health Promot Pract. 2012;13:738-746.

11. Rudd RE, Moeykens BA. Adult educators' perceptions of health issues and topics in adult basic education programs. In: NCSALL Report No 8. Cambridge, MA; 1999 [cited 2019 Jun 5]. Available from: www.ncsall.net/ fileadmin/resources/research/report8.pdf

12. McCaffery KJ, Morony S, Muscat DM, Smith SK, Shepherd HL, Dhillon HM, et al. Evaluation of an Australian health literacy training program for socially disadvantaged adults attending basic education classes: study protocol for a cluster randomised controlled trial. BMC Public Health. 2016;16(454).

13. Morony S, Lamph E, Muscat D, Nutbeam D, Shepherd H, Smith S, et al. Improving health literacy through adult basic education in Australia. Health Promot Int. 2018;33(5):867-77.

14. Ritchie J, Spencer LW, editors. Carrying out qualitative analysis. London: Sage Publications; C2003. (Qualitative research practice: a guide for social science students and researchers).

15. Muscat DM, Morony S, Smith SK, Shepherd HL, Dhillon HM, Hayen A, et al. Qualitative insights into the experience of teaching shared decision making within adult education health literacy programmes for lowerliteracy learners. Health Expect. 2017;20(6):1393-400. 
16. Muscat DM, Morony S, Trevena L, Hayen A Shepherd HL, Smith SK, et al. Skills for shared decisionmaking: evaluation of a health literacy program for consumers with lower literacy levels. Health Lit Res Pract. 2019;3(3 Suppl):S58-74.

17. Muscat DM, Shepherd HL, Nutbeam D, Morony S, Smith SK, Dhillon HM, et al. Developing verbal health literacy with adult learners through training in shared decision-making. Health Lit Res Pract. 2017;1(4):e257-68.

18. Muscat DM, Smith S, Dhillon HM, Morony S, Davis EL, Luxford K, et al. Incorporating health literacy in education for socially disadvantaged adults: an Australian feasibility study. Int J Equity Health. 2016;15(1):84.

19. Knowles MS, Holton EF, Swanson RA. The adult learner. New York, NY: Routledge; 2015.

20. Prins E, Toso BW, Schafft KA. It feels like a little family to me: social interaction and support among women in adult education and family literacy. Adult Educ Quart. 2009;59(4):335-52.

21. Albertini VL. Social networks and community support: sustaining women in need of community-based adult education programs. New Directions for Adult and Continuing Education. 2009;2009(122):23-32.

22. Freedman AM, Miner KR, Echt KV, Parker R, Cooper HL. Amplifying diffusion of health information in low-literate populations through adult education health literacy classes. J Health Commun. 2011;16(Suppl 3):119-33.

23. Tynell LL, Wimmelmann CL, Jervelund SS. Healthcare system information at language schools for newly arrived immigrants: a pertinent setting in times of austerity. Health Educ J. 2017:76(1):114-19.

24. Tassi A, Ashraf F. Health literate doctors and patients: the New York City Health Literacy Fellowship for first year medical students. Focus on Basics: Connecting Research \& Practice. 2008;9(B).

25. Edwards M, Wood F, Davies M, Edwards A. 'Distributed health literacy': Iongitudinal qualitative analysis of the roles of health literacy mediators and social networks of people living with a long-term health condition. Health Expect. 2015;18(5):1180-93.

26. von Wagner C, Steptoe A, Wolf MS, Wardle J. Health literacy and health actions: a review and a framework from health psychology. Health Educ Behav. 2009;36(5):860-77.
27. Australian Commission on Safety and Quality in Healthcare. Health literacy national statement. Sydney: ACSQHC; 2014 August [cited 2018 Jul 03]. Available from: www.safetyandquality.gov.au/publications/healthliteracy-national-statement

28. Wheelahan L. Not just skills: what a focus on knowledge means for vocational education. Journal of Curriculum Studies. 2015;47(6):750-62.

29. Tighe EL, Barnes AE, Connor CM, Steadman SC. Defining success in adult basic education settings: multiple stakeholders, multiple perspectives. Reading Research Quarterly. 2013;48(4):415-35.

\section{Copyright: (c) (i) (5)}

(C) 2019 Muscat et al. This article is licensed under the Creative Commons Attribution-NonCommercial-ShareAlike 4.0 International Licence, which allows others to redistribute, adapt and share this work non-commercially provided they attribute the work and any adapted version of it is distributed under the same Creative Commons licence terms. See: www.creativecommons.org/licenses/by-nc-sa/4.0/ 